\title{
Nonstationary Synchronization of Equatorial QBO with SAO in Observations and a Model
}

\author{
LE KUAI AND Run-LiE SHIA \\ Division of Geological and Planetary Sciences, California Institute of Technology, Pasadena, California \\ XUN JIANG \\ Department of Earth and Atmospheric Sciences, University of Houston, Houston, Texas \\ KA-KIT TUNG \\ Department of Applied Mathematics, University of Washington, Seattle, Washington \\ YUK L. YUNG \\ Division of Geological and Planetary Sciences, California Institute of Technology, Pasadena, California
}

(Manuscript received 16 June 2008, in final form 17 November 2008)

\begin{abstract}
It has often been suggested that the period of the quasi-biennial oscillation (QBO) has a tendency to synchronize with the semiannual oscillation (SAO). Apparently the synchronization is better the higher up the observation extends. Using $45 \mathrm{yr}$ of the 40-yr European Centre for Medium-Range Weather Forecasts (ECMWF) Re-Analysis (ERA-40) data of the equatorial stratosphere up to the stratopause, the authors confirm that this synchronization is not just a tendency but a robust phenomenon in the upper stratosphere. A QBO period starts when a westerly SAO (w-SAO) descends from the stratopause to $7 \mathrm{hPa}$ and initiates the westerly phase of the QBO (w-QBO) below. It ends when another w-SAO, a few SAO periods later, descends again to $7 \mathrm{hPa}$ to initiate the next w-QBO. The fact that it is the westerly but not the easterly SAO (e-SAO) that initiates the QBO is also explained by the general easterly bias of the angular momentum in the equatorial stratosphere so that the e-SAO does not create a zero-wind line, unlike the w-SAO. The currently observed average QBO period of 28 months, which is not an integer multiple of SAO periods, is a result of intermittent jumps of the QBO period from four SAO to five SAO periods. The same behavior is also found in the Two and a Half Dimensional Interactive Isentropic Research (THINAIR) model. It is found that the nonstationary behavior in both the observation and model is caused not by the 11-yr solar-cycle forcing but by the incompatibility of the QBO's natural period (determined by its wave forcing) and the "quantized" period determined by the SAO. The wave forcing parameter for the QBO period in the current climate probably lies between four SAO and five SAO periods. If the wave forcing for the QBO is tuned so that its natural period is compatible with the SAO period above (e.g., at 24 or 30 months), nonstationary behavior disappears.
\end{abstract}

\section{Introduction}

The quasi-biennial oscillation $(\mathrm{QBO})$ is an internal oscillation of the equatorial zonal wind in the stratosphere involving wave-mean flow interactions (Holton and Lindzen 1972; Lindzen and Holton 1968; Dunkerton 1997; Baldwin et al. 2001). There have been numerous

Corresponding author address: Le Kuai, Caltech, Planetary Science Division, 1200 S. California Blvd., Pasadena, CA 91125.

E-mail: kl@gps.caltech.edu observational studies of the QBO in the zonal wind, temperature, and ozone (e.g., Angell and Korshover 1970; Oltmans and London 1982; Hasebe 1983; Zawodny and McCormick 1991; Randel and Wu 1996; Pawson and Fiorino 1998). The equatorial QBO affects the polar stratosphere during winter, with the easterly phase of the QBO creating the condition for a more perturbed and warmer polar vortex (Holton and Tan 1980, 1982; Baldwin and Dunkerton 1999; Ruzmaikin et al. 2005). Therefore, the variation of the $\mathrm{QBO}$ period has additional significance, especially with respect to the 
timing of its phase relative to the Northern Hemisphere $(\mathrm{NH})$ winter, a phenomenon called seasonal synchronization (Baldwin et al. 2001).

The mean period of the QBO is around 28 months but is known to have interannual variations of several months about the average. When the QBO was first discovered (Reed et al. 1961; Ebdon and Veryard 1961), it was found to have a period of 26 months, with 13 months each of easterly and westerly phases at $50 \mathrm{hPa}$. Later it was reported (Tung and Yang 1994a,b) to have a period of 30 months based on the satellite record of 1979-92. For the period 1958-2002 spanned by the 40-yr European Centre for Medium-Range Weather Forecasts (ECMWF) Re-Analysis (ERA-40) data (Uppala et al. 2005), the mean QBO period is slightly less than 28 months (see below). It becomes a little longer than 28 months in the longest data record (rocketsonde and rawinsonde; 1953-2007), which is available from Free University of Berlin (FUB) (Baldwin et al. 2001; Fischer and Tung 2008). It is interesting to point out that the length of QBO periods is not constant; indeed, it is quite variable. Individual QBO episodes do not have a mean period normally distributed around a mean of 28 months. The period distribution appears to be bimodal. For example, the current estimate of 28 months as the mean QBO period is composed of a collection of individual periods of approximately 24 and 30 months (and an occasional 36 months in the longest records). Thus, the period of a QBO event is a multiple of the 6-month period of the semiannual oscillation (SAO). Because the SAO is seasonally synchronized with respect to Northern and Southern Hemisphere winters, the tendency of the QBO to synchronize with the SAO may be an important cause of its seasonal synchronization.

As pointed out by previous authors (Lindzen and Holton 1968; Gray and Pyle 1989; Dunkerton and Delisi 1997), the SAO's alternating easterly and westerly shear zones near the stratopause level serve to "seed" the QBO below. In particular, the onset of the westerly phase of the QBO (w-QBO) is tied to the downward propagation of the westerly phase of the SAO (w-SAO). A QBO period starts when the zero-wind line associated with the westerly shear zone of the SAO descends into the QBO region below. A QBO period ends when the next such westerly descent occurs after a multiple of SAO periods later and replaces the easterly phase of the QBO (e-QBO) below. In this way the QBO period is "quantized" in units of the SAO period. Lindzen and Holton (1968) found that "the appearance of successive westerly regimes at $30 \mathrm{~km}$ tends to be a multiple of 6 months." Because it is thought that there may be other factors that can affect the descent rate of the QBO from the upper to the lower stratosphere, in the lower stratosphere this property has been regarded more as a "tendency" than as a strict synchronization in reality (Dunkerton and Delisi 1997).

This paper is divided into five sections. In section 2, we will show that in fact the QBO period is better synchronized with the SAO than previously thought, using the ERA-40 reanalysis data that extend to the stratopause. We will also show that the decadal variation in the QBO period previously reported often takes the form of a discrete jump in integer multiples of SAO period. In section 3, we will use a model to explain why the QBO period variation is nonstationary in our current climate regime. A possible mechanism for QBO-SAO synchronization will be discussed in section 4 and it will be followed by conclusions in section 5 .

\section{QBO-SAO synchronization: Data analysis}

Figure 1 shows the height-time cross section of the equatorial zonal-mean zonal wind in the ERA-40 dataset up to $1 \mathrm{hPa}$. Baldwin and Gray (2005) compared the ERA-40 reanalysis zonal winds with the tropical rocketsonde and rawinsonde observations and concluded that the reanalysis provides "a good representation of tropical winds up to $2-3 \mathrm{hPa}$. The amplitudes of the QBO and the SAO derived from ERA-40 data match the rawinsonde and rocketsonde observations up to 2-3 hPa." They further suggested that "zonal-mean ERA-40 winds could be used, for most purposes, in place of rawinsonde station observations."

The 2-7-hPa region is where the $\mathrm{SAO}$, which is prominent in the stratopause level above, transitions to the QBO below. The presence of the QBO makes parts of the SAO difficult to see in the raw data shown in the top two panels of Fig. 1: During a QBO easterly phase, the w-SAO and the easterly phases of the SAO (e-SAO) are embedded in an easterly background and show up only as relative easterly maxima and minima. The alternating e-SAO and w-SAO are seen when we remove the QBO by averaging over all Januaries, Februaries, etc. in the entire ERA-40 record. This is done in the bottom two panels in Fig. 1 for $1-3 \mathrm{hPa}$. It is also seen in Fig. 1 that the w-QBO always starts with a w-SAO above, and one period of the QBO terminates when the westerly phase of the following QBO starts similarly with the descent of another w-SAO. This is as hypothesized originally by Lindzen and Holton (1968). The reason that it is the w-SAO but not its e-SAO that initiates a QBO below is explained as follows: Because the equatorial upper stratosphere is easterly without the SAO, the e-SAO does not introduce a zero-wind line, but the w-SAO does. A zero-wind line is where enhanced wave-mean flow interaction occurs. Therefore, at and immediately below the zero-wind line introduced 

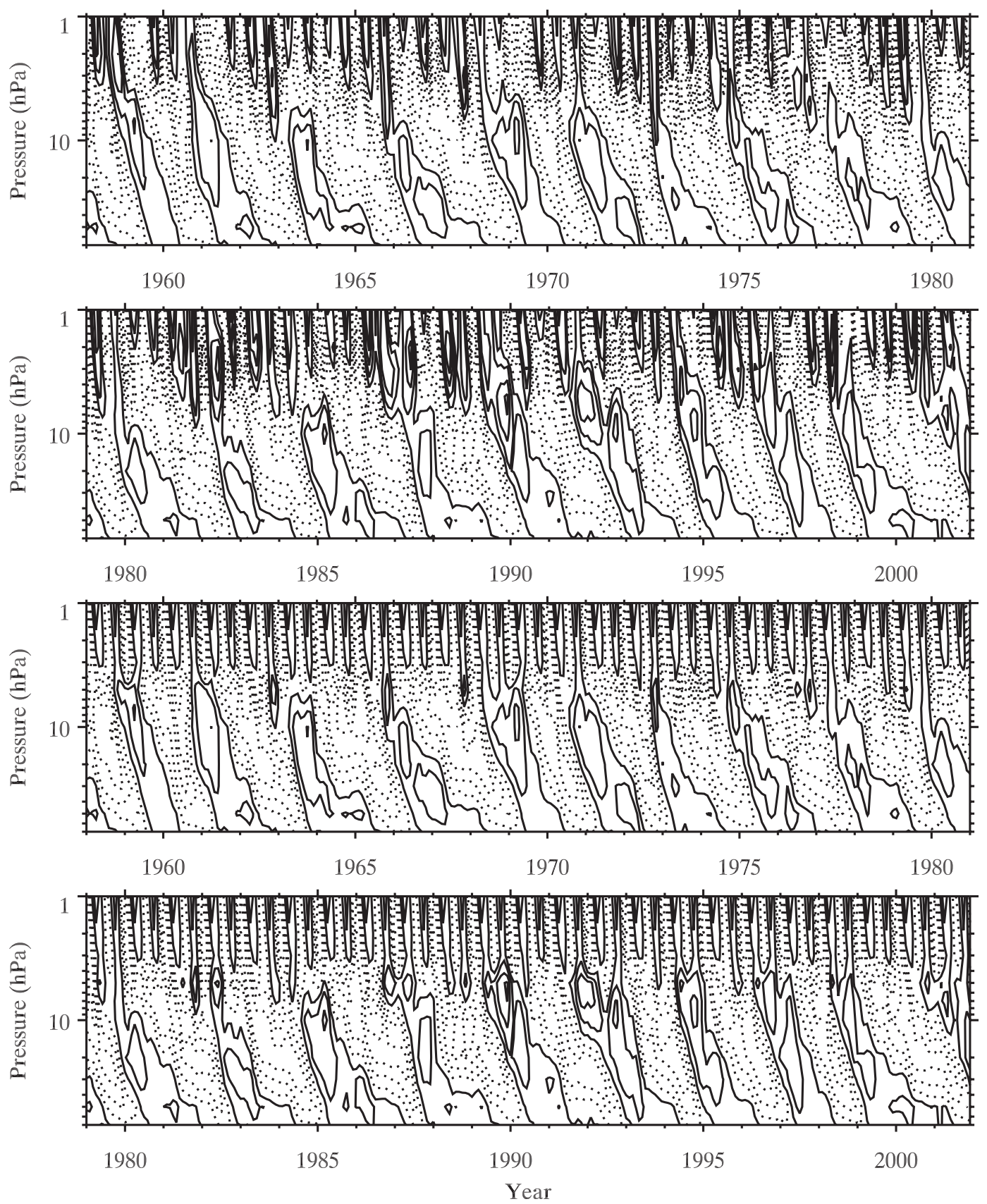

FIG. 1. (top and upper middle) Height-time cross section of the monthly-mean ERA-40 zonal-mean zonal wind. (lower middle and bottom) The zonal wind in the upper three levels $(1,2,3 \mathrm{hPa})$ is replaced by its seasonal climatology, which removes the QBO and shows the SAO more clearly. The contour interval is $10 \mathrm{~m} \mathrm{~s}^{-1}$. Positive values are plotted with solid lines. Negative values are plotted with dashed lines.

by the w-SAO, westerly wave momentum is deposited, causing the descent of the westerly shear zone, provided that the westerly waves are allowed to propagate up from the lower to the upper stratosphere. This happens when the westerly shear zone at the 50-70-hPa region, which shields waves of westerly phase speeds from propagating upward, breaks down at the appropriate time in the QBO's life cycle (see later). Therefore, not all w-SAOs initiate a QBO. Because a QBO period always starts and terminates with a w-SAO, the period of the QBO should be an integer multiple of the SAO period, at least in the upper stratosphere.

To verify this hypothesis, we show in Fig. 2a the QBO period at $5 \mathrm{hPa}$ in months. (The descent of the QBO in 

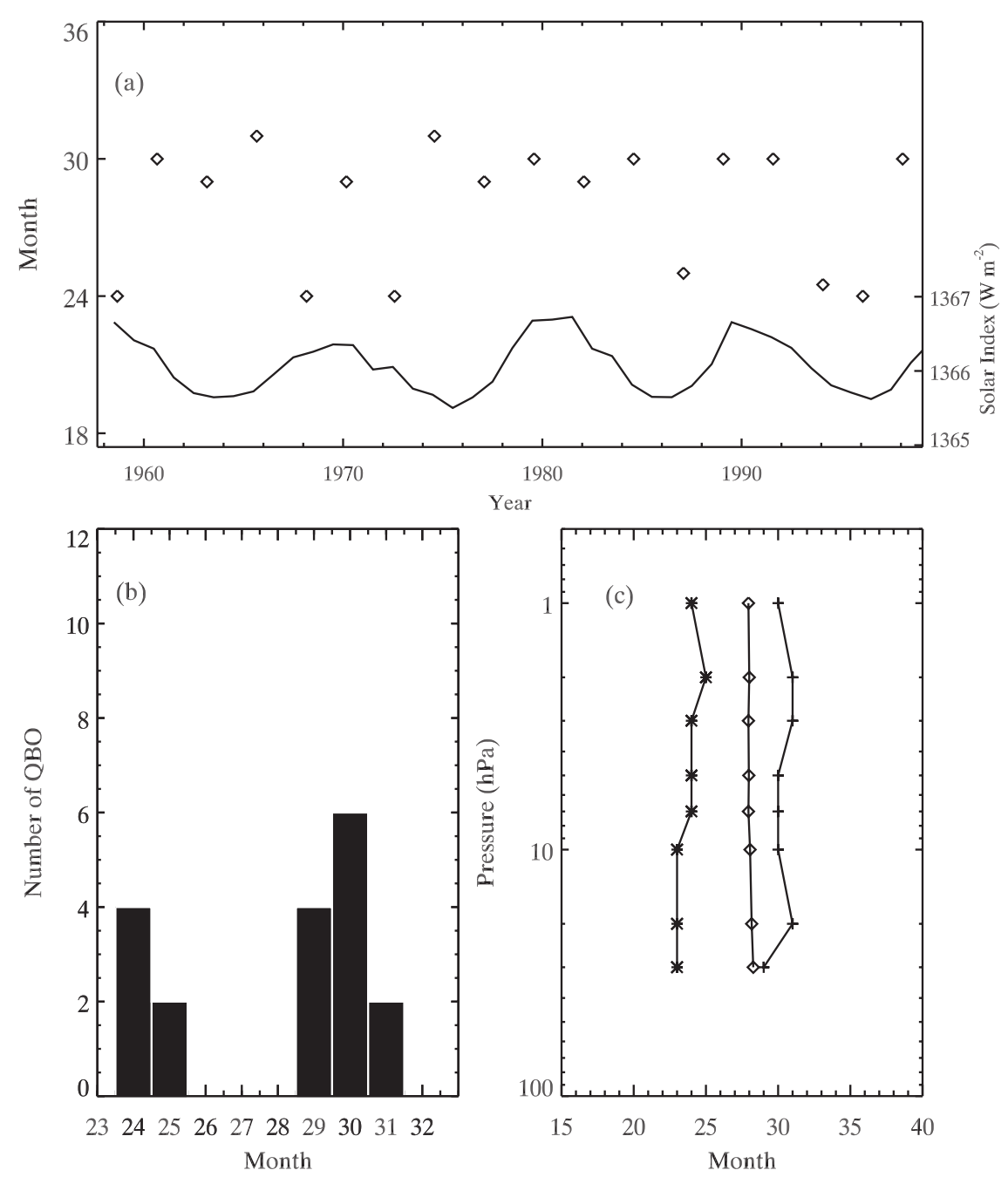

FIG. 2. (a) The QBO period in ERA-40 data at $5 \mathrm{hPa}$. The $\mathrm{QBO}$ period is counted in months (left scale), and the solid curve at the bottom is the solar cycle index ( $\mathrm{W} \mathrm{m}^{-2}$; right scale). (b) The histogram of the QBO period, counting the number of occurrences of the QBO period in months. (c) The QBO period as a function of pressure level. Asterisks (plus signs) denote the QBO during 1997 (1962) at $5 \mathrm{hPa}$; diamonds represent the mean QBO periods.

lower levels may be affected by the variable upwelling rate in the tropics; above the 5-hPa level, the SAO signal is comingled with the QBO signal.) A QBO period is measured in the raw monthly mean data by the time interval between the two zero crossings when the wind shifts from easterly to westerly. There are a few instances when a w-SAO descends to the usual QBO altitude at $5 \mathrm{hPa}$ but for some reason (possibly because of the persistence of the westerly wind below $50 \mathrm{hPa}$ that prevents the upward propagations of westerly waves) it fails to initiate a QBO below 5-7 hPa. One such example is just before 1963. The QBO period starts instead with the next SAO. Another such case occurs during the QBO of 1987-89. In this case it is clear, by looking at the QBO below $10 \mathrm{hPa}$, that the failed initi- ation of the QBO in mid-1986 should not be regarded as the starting point of the QBO, which actually started in 1987, one SAO period later (the QBO onsets in 1992 and 1984 behave similarly). After adjusting for these failed initiations of the QBO by some SAO, the QBO periods cluster around 24 and 30 months. Counting the periods of QBO and SAO by zero-wind crossing is not sufficiently accurate because of the presence of a variable mean easterly flow, which makes the SAO period appears to be not exactly 6 months, which accounts for the two cases of a 25-month period and the two cases of a 29-month period. One could alternatively count the QBO period in units of SAO period using the lower two panels of Fig. 1 and so find that the QBO periods are either four or five SAO periods long in the ERA-40 record. 
Figure $2 b$ is the histogram of the number of occurrences of the QBO period in months for the 45-yr ERA-40 data. It is seen that the reported mean period of 28 months for the QBO during this period of record is an average of six QBO periods each lasting four SAO periods (on average 24 months), and twelve QBO periods when there are five SAO periods (on average 30 months). In Fig. 2c, we show the vertical profiles of two individual QBO periods (one starting in 1962 (five SAOs) and the other in 1997 (four SAOs), along with the mean period of all the QBOs in the ERA-40 record. Not surprisingly, we see that the mean QBO period is constant with height [as also shown in Fig. 2c of Gabis and Troshichev (2006)]. Individual QBO periods are slightly more variable but can be regarded as almost constant, within \pm 1 month between 1 and $40 \mathrm{hPa}$, consistent with Fischer and Tung (2008), although we have found 2-month deviations in the lower stratosphere in some cases. Dunkerton (1990) found strong annual modulations of the onset of QBO even at 10 and $50 \mathrm{hPa}$. He found that the transition of the westerly to easterly $\mathrm{QBO}$ at $50 \mathrm{hPa}$ rarely occurs in $\mathrm{NH}$ winter.

Figure 2a shows that there are interesting decadal variations in the $\mathrm{QBO}$ period and that such variation takes the form of discrete jumps in integral multiples of SAO periods. The cause of the decadal variation of the QBO period in the lower stratosphere is a topic of current debate (Salby and Callaghan 2000; Soukharev and Hood 2001; Pascoe et al. 2005; Hamilton 2002; Fischer and Tung 2008). It is apparent from this figure, however, that such changes in QBO period in the upper stratosphere are not correlated (or anticorrelated) with the 11-yr solar cycle (SC); the total solar irradiance (Lean 2004) is indicated by the solid curve at the bottom of Fig. 2a. Note, however, that this result concerns the whole period of the QBO and does not necessarily apply to the question of whether the westerly portion of the QBO is correlated with the solar cycle.

An additional interesting result is that the jumps in the QBO period that we see in the ERA-40 data (in Fig. 1 or 2) above is not only seen in our model result (to be presented in section 3 ) with a periodic solar cycle forcing but is also present in model runs with perpetual solar maxima (SC-max) or solar minima (SC-min) or solar mean (SC-mean) forcing. This suggests that the nonstationary jumps in QBO period are probably not a result of the variable solar-cycle forcing but rather a property intrinsic to the QBO phenomenon itself.

\section{QBO from the THINAIR model}

\section{a. The model}

The Two and a Half Dimensional Interactive Isentropic Research (THINAIR) model is an isentropic coor- dinate chemical-radiative-dynamical model (Kinnersley and Harwood 1993). The model has zonally averaged dynamics and includes the three longest planetary waves, which are prescribed by observations at the tropopause level. For this study, the planetary wave forcing at the tropopause is prescribed to be annually periodic at the 1979-yr level derived from NCEP reanalysis data (Kalnay et al. 1996; Kistler et al. 2001), and repeated for all years. This choice reduces interannual variability of the planetary wave forcing, so that this variability in forcing is eliminated as a cause of the observed nonstationary behavior of the QBO period. It removes tropospheric variability of planetary waves but retains stratospheric variability of the planetary waves that is internally generated through wave propagation in a changing mean flow and wave-mean flow interaction. The model uses an isentropic vertical coordinate above $350 \mathrm{~K}$. Below $350 \mathrm{~K}$ a hybrid coordinate is used to avoid intersection of the coordinate layers with the ground. The version used in this study has 29 layers from the ground to $\sim 100 \mathrm{~km}$ for dynamics and 17 layers from the ground to $\sim 60 \mathrm{~km}$ for chemistry. The model has 19 meridional grid points evenly distributed from pole to pole. The QBO source term in the momentum equation uses parameterization of wave momentum fluxes from Kelvin and Rossby-gravity waves (in the form of a Kelvin wave with a westerly phase speed; Kinnersley and Pawson 1996).

The Upper Atmosphere Research Satellite (UARS) Solar Ultraviolet Spectral Irradiance Monitor (SUSIM) observations are used to simulate the 11-yr solar cycle. UARS SUSIM data consist of the solar spectrum in 119-400 nm during 1991-2002, with 1-nm resolution. The monthly data are extended to 1947-2005 using F10.7-cm as a proxy (Jackman et al. 1996). The yearly averaged data are integrated to give photon fluxes in wavelength intervals appropriate for the THINAIR model. The general performance of the model has been evaluated by Kinnersley and Pawson (1996). To avoid redoing the climatology with the new solar forcing, the UARS/SUSIM SC-mean is scaled to the SC-mean of the THINAIR model, which is based on Lean (2004).

\section{b. Time-varying solar cycle run}

A 200-yr run is made using the realistic, time-varying solar cycle forcing for 1964-95 from UARS SUSIM (extended as described above) and repeated thereafter. Even in this long run, the period of the QBO does not settle down to a fixed number; instead, it still executes apparently irregular jumps in period. Another 400-yr run is carried out to show that the statistical properties in the 200-yr run have settled down (in particular, the histograms of the distributions for the 200- and 400-yr runs are the same). The behavior of the $\mathrm{QBO}$ period in 

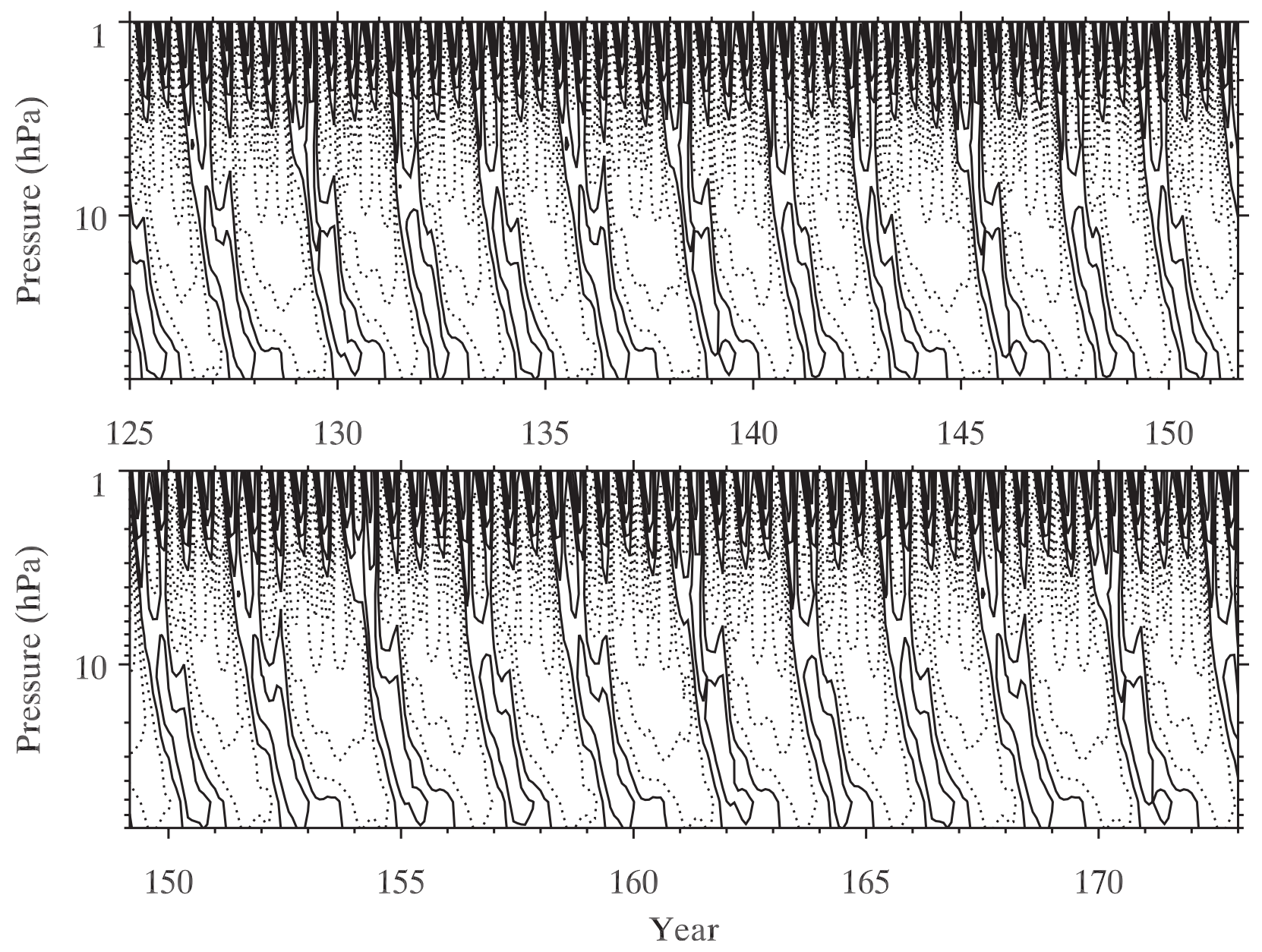

FIG. 3. Height-time cross section of zonal-mean zonal wind for the SC-varying model case. Contour intervals and lines as in Fig. 1.

the model is remarkably similar to the observation discussed above, including features such as the QBO westerly being synchronized with the SAO westerly in the upper stratosphere and the QBO westerly sometimes stalling below $50 \mathrm{hPa}$. As in the observation, some SAOs also fail to initiate a QBO in the model, but the frequency of such occurrences is smaller in the model. Importantly, the model QBO period also jumps from four SAO periods to five SAO periods in a nonstationary manner. Figure 3 shows a height-time cross section of the zonal-mean zonal wind at the equator from the model. Figure 4 can be used to compare the period of the model QBO with that from ERA-40 shown in Fig. 2. The number of five $\mathrm{SAO}$ periods is about equal to the number of four SAO periods in both the 200- and 400-yr runs and so the frequency of five SAO periods relative to four SAO periods is less than in the $45 \mathrm{yr}$ of the ERA- 40 data. However, in different smaller time segments of about 45 yr from the model, corresponding to the period of ERA40 data, the distribution can shift. In the segment shown, which is from year 126 to year 172 in the 400 -yr model run, there are more five SAO periods than four SAO periods, as in the EAR-40 data (Fig. 4b).

\section{c. Perpetual solar forcing runs}

Additionally, we perform constant solar-cycle forcing experiments in our model to answer the question of whether the nonstationary nature of the QBO period is caused by the fact that the solar-cycle forcing is time varying. (It should be pointed out that we still have the seasonal cycle in the "perpetual" solar runs.) Figure 5 is similar to Fig. 3 except for perpetual SC-mean forcing in the 200-yr runs. There are no qualitative differences between the perpetual solar forcing run and the variable solar-cycle forcing run. In particular, the QBO period still jumps irregularly from four SAO to five SAO periods and back. We therefore conclude that the nonstationary nature of the QBO period is not caused by decadal variability in the solar-cycle forcing. 

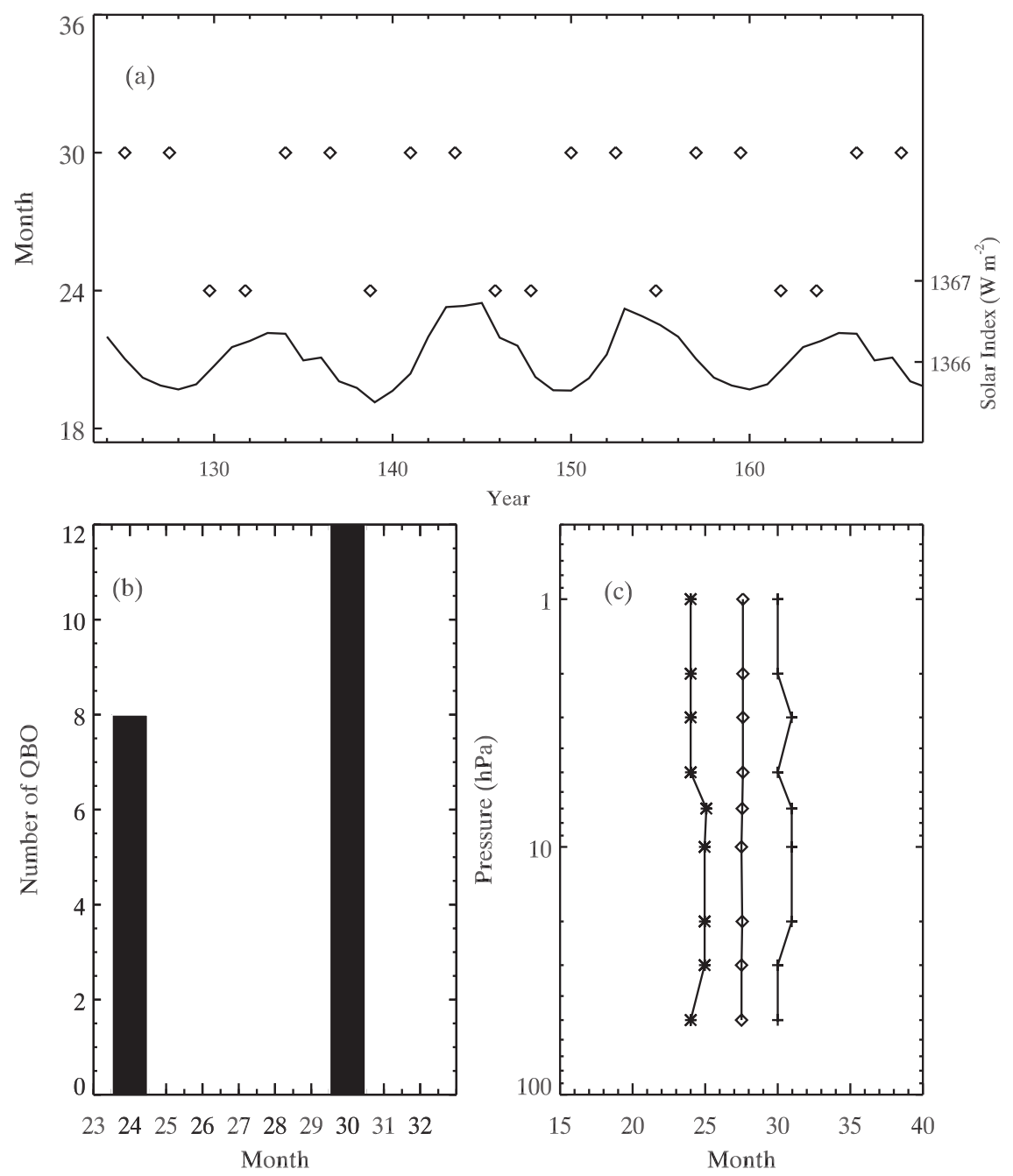

FIG. 4. As in Fig. 2, but for model results for the SC-varying case. The solid curve is the solar index, as in Fig. 2, but repeated from 1964 to 1995 to cover 400 yr. Here we show a subsegment of $46 \mathrm{yr}$ out of the 400-yr run. In (c), the asterisks represent the QBO during year 165 and plus signs represent the QBO during year 128. Diamonds represent the mean QBO periods during these $46 \mathrm{yr}$.

\section{A possible mechanism for QBO-SAO synchronization}

In the original theory of the QBO by Lindzen and Holton (1968) the presence of the mesospheric SAO above the QBO is needed to restore the flow to a direction that is opposite to the zonal flow at the lower stratosphere. Later publications, however, have tended to deemphasize the essential role of the SAO in seeding the QBO, following the conclusion of Holton and Lindzen (1972) that "the mesospheric semiannual oscillation, while important, is no longer absolutely essential to the overall theory." [Holton was reportedly uneasy with this statement; see Lindzen (1987).] Plumb
(1977) also argued that the SAO is unnecessary for the QBO. Neither model, however, incorporated the easterly bias of the equatorial zonal flow on a rotating planet: Without the SAO the equatorial upper stratosphere near the stratopause is generally easterly, making it difficult for initiating a w-QBO. Note that the assumed form of mean zonal flow is westerly in the upper stratosphere in the original model of Lindzen and Holton (1968), and there is an SAO in the numerical model of Holton and Lindzen (1972) that provided the westerly flow in the upper levels. Although it is not "absolutely essential" to have the SAO because a highly nonlinear wave breaking event can initiate a westerly descent by itself, without the SAO the initiation of the 

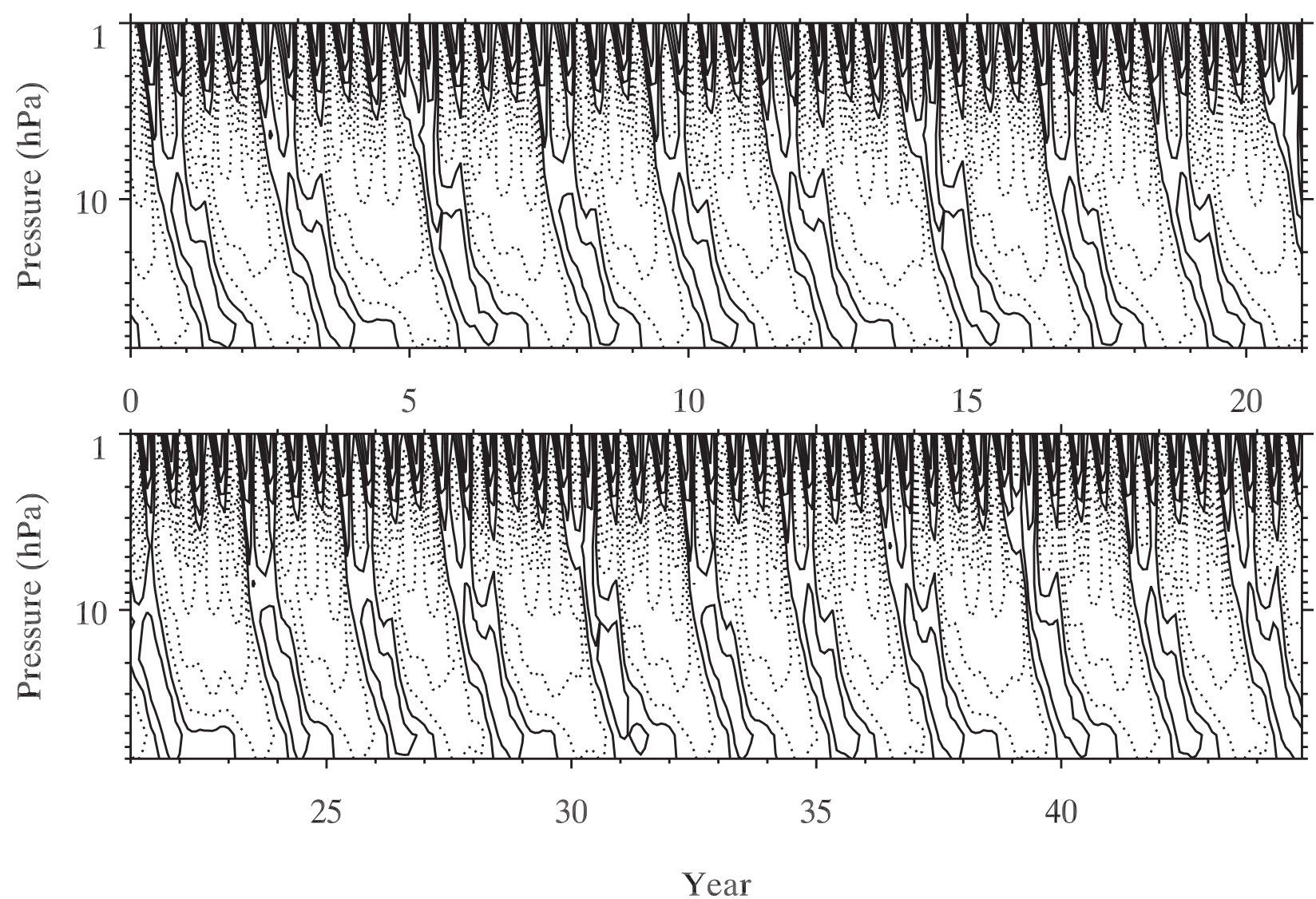

FIG. 5. Height-time cross section of zonal-mean zonal wind for the SC-mean case. Contour intervals and lines as in Fig. 1.

westerly descent probably would have occurred higher up, in the mesosphere.

As the w-QBO descends into the lower stratosphere with denser and denser air, it stalls usually at the 70-hPa level. Upward-propagating waves with phase speed in the same direction as the lower stratospheric zonal flow (westerly in this phase of the QBO) meet their critical level in the lower stratosphere (where the phase speed equals the mean wind speed) and are absorbed near or below this level. They are thus prevented from propagating farther upward. Waves of opposite (easterly) phase speed, however, can freely propagate up. These (easterly) waves encounter an easterly zonal flow, deposit their easterly momentum, and subsequently bring the easterly jet to lower and lower altitudes, replacing the westerly flow below it. In the simple models mentioned above, the westerly jet near $70 \mathrm{hPa}$ becomes thinner and thinner in the process and eventually breaks because of flow instability. This then allows the propagation of westerly waves into the upper stratosphere. Because the equatorial upper stratosphere and mesosphere are generally easterly without the SAO, these westerly waves do not meet their critical level and the descent of the westerly zonal flow cannot be initiated [in the quasi-linear model of Lindzen and Holton (1968)] in the absence of the SAO. Therefore, the SAO plays an important role in initiating the alternating easterly and westerly descents of the zonal wind in a QBO. It follows then that the period of the QBO, at least in the upper stratosphere, should be synchronized with the SAO. In particular, the westerly phase of the QBO should be synchronized with the w-SAO, as it is observed to do in the ERA-40 data presented in section 2. The initiation of the easterly phase of the QBO does not need the SAO.

The above discussion explains that given there is a SAO at the stratopause, the initiation of the westerly phase of the QBO should be synchronized with the w-SAO. It then follows that the QBO period in the upper stratosphere should be an integer multiple of the SAO period. The remaining question is this: why does the QBO period jump from one SAO multiple to another SAO multiple? One suggestion might be that it is the variable solar-cycle forcing that alters the QBO period, but this effect is found to the negligible in our model. There is no correlation or anticorrelation of the QBO period with the solar cycle in either the observation or in 


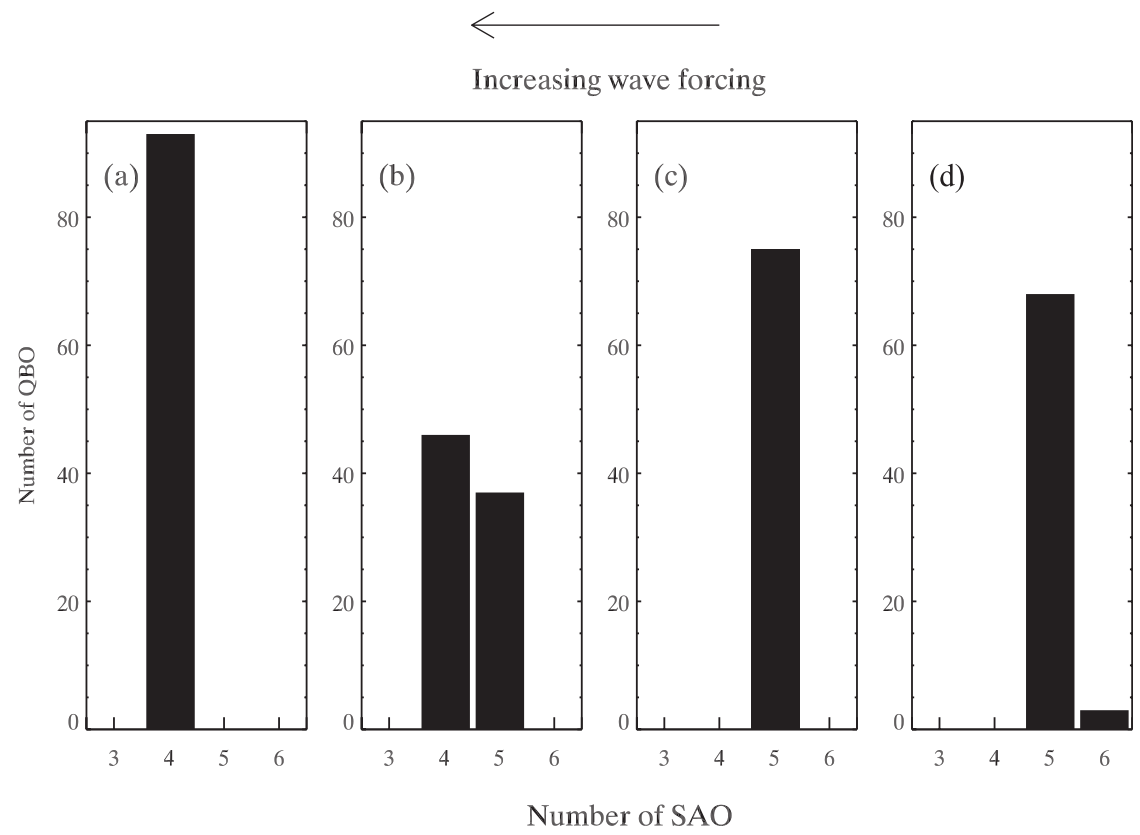

FIG. 6. Histogram of the periods of the QBO for different wave forcings that shows the frequency of occurrence of QBOs whose periods are four, five, or six SAO periods. See Table 1 for details; case b is the baseline case, as in Fig. 5 .

the model. [We are not addressing here the issue of whether the westerly phase duration of the QBO is anticorrelated with the solar cycle, as reviewed by Fischer and Tung (2008); the modeling work is left to a separate paper.] Furthermore, we find that the nonstationary jumps still occur even when there is no solarcycle variability. An explanation of this nonstationary behavior appears to be the following: the intrinsic period of the QBO is determined by the internal dynamics of the wave-mean flow system. Plumb (1977) gave a simple formula for the simplified cases: the period $T$ is proportional to the cube of the phase speed $c$ of the forcing wave and inversely proportional to the magnitude of the wave forcing $F$. This intrinsic period, however, may not be compatible with the period determined by the SAO. For the case where the intrinsic QBO period lies between four and five SAO periods, a predicted transition from e-QBO to w-QBO would have to occur in a SAO easterly flow, which is difficult. Instead the transition would be delayed to the next w-SAO phase. This is consistent with the conceptual model discussed in Lindzen and Holton (1968); however, it has not been pointed out previously that this is the cause for the nonstationary behavior. Nonstationary jumps are needed so that the long-term averaged period is close to the intrinsic period. Compatibility with the QBO's period is necessary and explains why not all w-SAOs initiate a QBO. As discussed previously, the initiation of the w-QBO by a w-SAO has to wait until in the life cycle of the QBO in the lower stratosphere when westerly equatorial waves are not blocked from propagating upward.

If the intrinsic period of the QBO is already an integer multiple of the SAO period, the QBO period would be phase-locked with that SAO multiple and the nonstationary jumps would disappear if this explanation is correct.

\section{Parametric study}

We can test this hypothesis in our model in a parametric study by changing the QBO wave forcing $F$. We show that in a parametric diagram of the QBO period involving $F$, nonstationary regimes are separated by islands (actually lines) of phase-locking (and hence stationary behavior).

The westerly forcing by a Kelvin wave is parameterized as in Gray and Pyle (1989); the easterly forcing in this model by Rossby-gravity waves differs from the Kelvin wave only in its opposite zonal phase speed (Kinnersley and Pawson 1996). The expression for the wave-induced zonal force per unit mass is defined as follows:

$$
F(z)=\exp \left(\frac{z-z_{0}}{H}\right) \sum_{i=1}^{2} A_{i} R\left(z, c_{i}\right) \exp \left[-P_{i}(z)\right],
$$

where

$$
R\left(z, c_{i}\right)=\frac{\alpha(z) N}{k_{i}\left(\bar{u}-c_{i}\right)^{2}} \quad \text { and }
$$




$$
P_{i}(z)=\int_{z_{0}}^{z} R(z) d z
$$

Here, $i=1$ is for the Kelvin wave and $i=2$ is for the Rossby-gravity wave; $c_{1}(>0)$ is the phase speed $\left(\mathrm{m} \mathrm{s}^{-1}\right)$ for Kelvin wave whereas $c_{2}(<0)$ is the Rossbygravity wave phase speed, and $A_{i}$ is the amplitude of vertical momentum flux at $z_{0}\left(\mathrm{~m}^{2} \mathrm{~s}^{-1}\right)$. For the baseline case in Fig. $6 \mathrm{~b}, A_{1}=2.7 \times 10^{-3} \mathrm{~m}^{2} \mathrm{~s}^{-1}$ and $A_{2}=$ $-2.7 \times 10^{-3} \mathrm{~m}^{2} \mathrm{~s}^{-1}, \alpha(z)$ is the thermal damping rate, $N$ is the Brunt-Väisäla frequency, $k_{i}$ is the zonal wavenumber, and $\bar{u}$ is the zonal wind speed.

In our study of the sensitivity of the QBO period to wave forcing, the phase speed is not changed. We tune the total wave forcing $F(z)$ on the QBO in our model by varying the parameters $A_{i}$ in the equations by a constant factor (see Table 1) from their baseline values.

The result is shown in Fig. 6. As predicted by Plumb (1977), the QBO period decreases (increases) as we increase (decrease) $F$ from our baseline case of SC-mean (Fig. 6b). For a value of $F$ that yields a mean QBO period of 24 or 30 months, nonstationary behavior disappears because now the intrinsic period is synchronized with the SAO period, being an integer multiple of the latter's period. Nonstationary behavior returns when the magnitude of $F$ lies between and away from these values.

\section{Conclusions}

Using ERA-40 data, which extend to the stratopause region and encompass both the $\mathrm{SAO}$ and $\mathrm{QBO}$, we find that the period of the QBO is always an integer multiple of the SAO period. The w-QBO always corresponds to a w-SAO above. A plausible explanation is provided, consistent with the original explanation of Lindzen and Holton (1968). Although an SAO is not "absolutely necessary" for seeding the QBO below, the w-SAO facilitates the initiation of the w-QBO. Because the equatorial upper stratosphere has an easterly bias in the absence of the SAO, as it should by angular momentum considerations on an eastward-rotating planet, the initiation of the w-QBO would have become more difficult in the absence of the SAO and thus should have occurred higher up in the mesosphere than observed. We have also shown that because there is very little variation of the QBO period in the vertical (within limits of about 1 to 2 months), the same synchronization with the SAO should also hold throughout the stratosphere, to that accuracy.

A second interesting feature of the observed behavior of the QBO period is that it jumps from four-SAO to five-SAO periods and back in a seemingly random way. This nonstationary behavior is explained using a model. In our model we show that the nonstationary behavior is
TABLE 1. Parameters used to force the QBO in the THINAIR model.

\begin{tabular}{ccc}
\hline \hline $\begin{array}{c}\text { Phase speed } \\
c\left(\mathrm{~m} \mathrm{~s}^{-1}\right)\end{array}$ & Kelvin wave & Rossby-gravity wave \\
& 25 & -30 \\
Case & $A_{1} /\left(A_{1}\right)_{\text {baseline }}$ & $A_{2} /\left(A_{2}\right)_{\text {baseline }}$ \\
(a) & 1 & 1.1 \\
(b) & 1 & 1 \\
(c) & 0.91 & 1 \\
(d) & 0.83 & 1.05 \\
\hline
\end{tabular}

not due to the fact that the solar-cycle forcing is time varying because the same behavior remains when we remove the solar cycle in our perpetual SC-mean run (see the comparison between Figs. 3 and 5). An alternative explanation is that the magnitude of wave forcing in our current climate is consistent with a QBO period intermediate between four and five SAOs, and so the period of the QBO determined by its internal forcing mechanism is incompatible with the external constraint provided by the SAO. To maintain synchronization with the SAO period, the QBO period jumps in a nonstationary way so that a long-term average of its period is compatible with its intrinsic wave forcing. If this explanation is correct, then we should be able to find a different behavior for a different wave forcing, larger or smaller than the value for the current climate, for which the intrinsic period is an integer multiple of the SAO period. Under such a condition, the nonstationary behavior should disappear. This is indeed the case, and the QBO period locks into periods of four (or five) SAOs when the relative forcing is increased (or decreased) by $\sim 10 \%$ (see Fig. 6 ).

Acknowledgments. This work was supported in part by NASA Grants NAG1-1806 and NNG04GN02G to the California Institute of Technology. K. K. Tung's research was supported by NSF Grants ATM 0332364 and ATM 0808375 to University of Washington. We thank A. Ruzmaikin and J. Feynman for useful discussions and K. F. Li for his calculation of the solar cycle variation in solar flux data and helpful suggestions. We also acknowledge help in improving the paper from M. C. Liang, N. Heavens, X. Guo, A. Soto, T. Lee, X. Zhang, P. S. Jiang, Y. C. Chen, D. Yang, and C. D. Camp.

\section{REFERENCES}

Angell, J. K., and J. Korshover, 1970: Quasi-biennial, annual, and semiannual zonal wind and temperature harmonic amplitudes and phases in the stratosphere and low mesosphere of the Northern Hemisphere. J. Geophys. Res., 75, 543-550. 
Baldwin, M. P., and T. J. Dunkerton, 1999: Propagation of the Arctic Oscillation from the stratosphere to the troposphere. J. Geophys. Res., 104 (D24), 30 937-30 946.

- , and L. J. Gray, 2005: Tropical stratospheric zonal winds in ECMWF ERA-40 reanalysis, rocketsonde data, and rawinsonde data. Geophys. Res. Lett., 32, L09806, doi:10.1029/ 2004GL022328.

_ - and Coauthors, 2001: The quasi-biennial oscillation. Rev. Geophys., 39, 179-229.

Dunkerton, T. J., 1990: Annual variation of deseasonalized mean flow acceleration in the equatorial lower stratosphere. J. Meteor. Soc. Japan, 68, 499-508.

- 1997: The role of gravity waves in the quasi-biennial oscillation. J. Geophys. Res., 102 (D22), 26 053-26 076.

— cillation and stratopause semiannual oscillation. J. Geophys. Res., 102 (D22), 26 107-26 116.

Ebdon, R. A., and R. G. Veryard, 1961: Fluctuations in tropical stratospheric winds. Meteor. Mag., 90, 125-143.

Fischer, P., and K. K. Tung, 2008: A reexamination of the QBO period modulation by the solar cycle. J. Geophys. Res., 113, D07114, doi:10.1029/2007JD008983.

Gabis, I., and O. Troshichev, 2006: Influence of solar UV irradiance on the quasi-biennial oscillation of zonal winds in the equatorial stratosphere. J. Atmos. Solar-Terr. Phys., 68, 1987-1999.

Gray, L. J., and J. A. Pyle, 1989: A two-dimensional model of the quasi-biennial oscillation of ozone. J. Atmos. Sci., 46, 203-220.

Hamilton, K., 2002: On the quasi-decadal modulation of the stratospheric QBO period. J. Climate, 15, 2562-2565.

Hasebe, F., 1983: Interannual variations of global total ozone revealed from Nimbus 4 BUV and ground-based observations. J. Geophys. Res., 88 (C11), 6819-6834.

Holton, J. R., and R. S. Lindzen, 1972: An updated theory for the quasi-biennial cycle of the tropical stratosphere. J. Atmos. Sci., 29, 1076-1080.

- and H. C. Tan, 1980: The influence of the equatorial quasibiennial oscillation on the global circulation at $50 \mathrm{mb}$. J. Atmos. Sci., 37, 2200-2208.

— ern Hemisphere lower stratosphere. J. Meteor. Soc. Japan, 60, 140-148.

Jackman, C., E. L. Fleming, S. Chandra, D. B. Considine, and J. E. Rosenfield, 1996: Past, present, and future modeled ozone trends with comparisons to observed trends. J. Geophys. Res., 101 (D22), 28 753-28 767.

Kalnay, E., and Coauthors, 1996: The NCEP/NCAR 40-Year Reanalysis Project. Bull. Amer. Meteor. Soc., 77, 437-471.

Kinnersley, J. S., and R. S. Harwood, 1993: An isentropic twodimensional model with an interactive parameterization of dynamical and chemical planetary-wave fluxes. Quart. J. Roy. Meteor. Soc., 119, 1167-1193.
, and S. Pawson, 1996: The descent rates of the shear zones of the equatorial QBO. J. Atmos. Sci., 53, 1937-1949.

Kistler, R., and Coauthors, 2001: The NCEP-NCAR 50-Year Reanalysis: Monthly means CD-ROM and documentation. Bull. Amer. Meteor. Soc., 82, 247-267.

Lean, J., 2004: Solar irradiance reconstruction. IGBP PAGES/ World Data Center for Paleoclimatology Data Contribution Series 2004-035, NOAA/NGDC Paleoclimatology Program, Boulder CO. [Available online at http://gcmd.nasa.gov/records/ GCMD_NOAA_NCDC_PALEO_2004-035.html.]

Lindzen, R. S., 1987: On the development of the theory of the QBO. Bull. Amer. Meteor. Soc., 68, 329-337.

— , and J. R. Holton, 1968: A theory of the quasi-biennial oscillation. J. Atmos. Sci., 25, 1095-1107.

Oltmans, S. J., and J. London, 1982: The quasi-biennial oscillation in atmospheric ozone. J. Geophys. Res., 87, 8981-8989.

Pascoe, C. L., L. J. Gray, S. A. Crooks, M. N. Juckes, and M. P. Baldwin, 2005: The quasi-biennial oscillation: Analysis using ERA-40 data. J. Geophys. Res., 110, D08105, doi:10.1029/ 2004JD004941.

Pawson, S., and M. Fiorino, 1998: A comparison of reanalyses in the tropical stratosphere. Part 2: The quasi-biennial oscillation. Climate Dyn., 14, 645-658.

Plumb, R. A., 1977: Interaction of two internal waves with meanflow implications for the theory of quasi-biennial oscillation. J. Atmos. Sci., 34, 1847-1858.

Randel, W. J., and F. Wu, 1996: Isolation of the ozone QBO in SAGE II data by singular-value decomposition. J. Atmos. Sci., 53, 2546-2559.

Reed, R. J., W. J. Campbell, L. A. Rasmussen, and D. G. Rogers, 1961: Evidence of a downward-propagating, annual wind reversal in the equatorial stratosphere. J. Geophys. Res., 66 , 813-818.

Ruzmaikin, A., J. Feynman, X. Jiang, and Y. L. Yung, 2005: Extratropical signature of the quasi-biennial oscillation. J. Geophys. Res., 110, D11111, doi:10.1029/2004JD005382.

Salby, M., and P. Callaghan, 2000: Connection between the solar cycle and the QBO: The missing link. J. Climate, 13, 328338.

Soukharev, B. E., and L. L. Hood, 2001: Possible solar modulation of the equatorial quasi-biennial oscillation: Additional statistical evidence. J. Geophys. Res., 106, 14 855-14 868.

Tung, K. K., and H. Yang, 1994a: Global QBO in circulation and ozone. Part I: Reexamination of observational evidence. J. Atmos. Sci., 51, 2699-2707.

— II: A simple mechanistic model. J. Atmos. Sci., 51, 2708-2721.

Uppala, S. M., and Coauthors, 2005: The ERA-40 re-analysis. Quart. J. Roy. Meteor. Soc., 131, 2961-3012.

Zawodny, J. M., and M. P. McCormick, 1991: Stratospheric Aerosol and Gas Experiment II measurements of the quasi-biennial oscillations in ozone and nitrogen dioxide. J. Geophys. Res., 96 (D5), 9371-9377. 